\title{
As demandas requeridas para o trabalhador com deficiência no Brasil na década de 1990
}

\author{
Ireni Marilene Zago Figueiredo* \\ Jackson Johann**
}

\section{Resumo}

As mudanças que ocorreram na esfera da produção capitalista conferiram novas perspectivas e demandas para a reestruturação do ensino médio e profissional, ocorrido na segunda metade dos anos de 1990. A preocupação da inserção da pessoa com deficiência no mercado de trabalho situa-se na referida década, sendo que a partir do Processo de Educação Profissional e Colocação no Trabalho (PECT), as APAES do Brasil objetivaram ultrapassar o caráter ocupacional e terapêutico que a profissionalização tinha até então. Objetiva-se, a partir da análise documental, demonstrar que o PECT, sustentado pela Federação Nacional das APAES (FENAPAES), ao estar inserido na dinâmica do processo de reestruturação produtiva refletiu, em certa medida, as competências e habilidades básicas exigidas para o trabalhador com deficiência na década de 1990.

Palavras-chave: Política de educação profissional; Pessoa com deficiência; Processo de educação profissional e colocação no trabalho (PECT).

\footnotetext{
* Professora Doutora do Colegiado do Curso de Pedagogia e do Mestrado em Educação da Universidade Estadual do Oeste do Paraná (Unioeste) - Campus de Cascavel - Paraná.

** Mestre em Educação pelo Programa de Pós-Graduação em educação da Universidade Estadual do Oeste do Paraná (Unioeste) - Campus de Cascavel - Paraná.
}

Disponível em: <http://www.ufsm.br/revistaeducacaoespecial> 


\title{
Required demands for the worker with deficiency in Brazil during the decade of 1990
}

\begin{abstract}
The changes which occurred in the scope of capitalist production have set new perspectives and demands for the restructuring of both high school level and professional education that happened in the second half of the nineties. The concern with the insertion of the person with disability in the labor market is situated in the previously mentioned decade. From the Process of Professional Education and Work Placement (in Portuguese: Processo de Educação Profissional e Colocação no Trabalho - PECT), the APAES of Brazil aimed to further the occupational and therapeutic character that professionalization had until then. Thus, based on document analysis, the aim of this study is to demonstrate that the PECT, supported by the National Federation of APAES (FENAPES) and introduced in the dynamics of productive restructuring process, reflected, in a sense, the basic competencies and skills required from the worker with disability in the decade of 1990.
\end{abstract}

Keywords: Professional education policy; Person with disability; Process of professional education and work placement (PECT).

Até os anos de 1990, as Oficinas Protegidas foram predominantes nas instituições especializadas, constituindo uma ação extensiva à Educação Especial (ARAÚJO, 2003, p. 141). Todavia, as mudanças que ocorreram na esfera da produção capitalista conferiram novas perspectivas e demandas para a reestruturação do ensino médio e profissional, ocorrido na segunda metade dos anos de 1990. É, portanto, a partir do processo de reorganização dos processos de trabalho, somado ao processo de expansão do neoliberalismo que, na década de 1990, várias reformas foram realizadas no Brasil. Dentre as reformas podemos citar, por exemplo, a reforma do Estado, da Previdência Social, da Saúde, da Educação Básica, da Educação Profissional para a pessoa com deficiência, etc.

As reformas efetivadas no Brasil convergem com as orientações dos Organismos Internacionais, tais como o Banco Mundial, o Fundo Monetário Internacional, o Banco Interamericano de Desenvolvimento e o Banco Internacional para a Reconstrução e Desenvolvimento, os quais contribuem significativamente para assegurar a hegemonia do capital dentro do país (DEITOS, 2001, p. 32). 
Nesse processo de recuperação da estrutura produtiva para melhoria dos níveis de acumulação, organismos internacionais [...] contribuem significativamente para a explicitação da forma nova de pensar e de educar. A partir da década de 1990, investem e financiam os meios e os modos mais seguros para universalizar a transformação dos comportamentos humanos. (NAGEL, 2010, p. 60)

A reforma da educação básica, entre outras coisas, tem em vista, a qualificação do novo homem necessário ao padrão flexível de acumulação ${ }^{1}$ (HOTZ; ZANARDINI, 2009, p. 134) sendo que, na década de 1990, as políticas educacionais para o ensino médio e a educação profissional consideram a existência de uma relação direta entre o nível educacional, a colocação no mercado de trabalho, o aumento salarial, a produtividade industrial e o desenvolvimento do país (HOTZ, 2010, p. 59). trabalhadores:

É nesse contexto que se intensifica a competição entre os

Com os novos controles nos processos de trabalho introduzidos pelo toyotismo, baseado no trabalho em equipe e no controle da produção através de um sistema de encadeamento de luzes que indicam o ritmo da produção, a competição entre os próprios trabalhadores é muito mais intensificada do que era no fordismo. (ROSA, 2009, p. 135)

A relação da pessoa com deficiência com o trabalho e com a sociedade, permaneceu praticamente inalterada, apesar das condições materiais objetivas alcançadas com o estágio de desenvolvimento das forças produtivas e das relações sociais de produção. $O$ processo de produção capitalista, visando extrair dos trabalhadores assalariados o máximo de produtividade e, consequentemente, de lucro, continuou priorizando o uso da força de trabalho que não fugisse ao padrão de normalidade aceitável e que não interferisse negativamente na produção da taxa da mais-valia (ROSA, 2009, p. 85).

Para formar o trabalhador que o sistema produtivo precisa, a escola constitui uma das estratégias do Estado neoliberal, ao pressupor que os novos modelos de organização do trabalho exigem novas aptidões, capacidades e atitudes, as quais a escola poderá contribuir. A qualificação incluiria um conjunto de habilidades e de competências, tais como: a responsabilidade, a cooperação, o engajamento com os objetivos da empresa, a iniciativa e a capacidade de resolver problemas, a disposição para continuar aprendendo e se adaptar às mudanças (HOTZ, 2010, p. 51-52). 
Hotz (2010, p. 52) destaca que para Duarte (2003, p. 11) essa adaptação exigida do trabalhador sintetiza o lema do "aprender a aprender", expresso no Relatório para a Organização das Nações Unidas para a Educação (UNESCO), da Comissão Internacional sobre Educação para o Século XXI, conhecido como Relatório "Jacques Delors".

Nos documentos da Federação Nacional das APAES (FENAPAES) é possível identificar a preocupação com as quatro aprendizagens fundamentais que, ao longo de toda a vida seriam, de algum modo, os pilares do conhecimento para os indivíduos: "aprender a conhecer, isto é, adquirir os instrumentos da compreensão; aprender a fazer, para poder agir sobre o meio envolvente; aprender a viver juntos, a fim de participar e cooperar com os outros em todas as atividades humanas; finalmente aprender a ser, que integra as três precedentes" (DELORS, 2001, p. 89).

A FENAPAES sustenta que as habilidades específicas estariam mais relacionadas ao trabalho e compreenderiam o "saber fazer" e o "saber ser":

\begin{abstract}
As habilidades específicas estão mais relacionadas ao trabalho e dizem respeito ao 'saber fazer' e ao 'saber ser', como fazer um artesanato, trabalhar na horta ou na marcenaria. São exigidas nos postos de trabalho e profissões, em uma ou mais áreas correlatas. Implicam conhecimento técnico e competências que garantem a empregabilidade polivalente em longo prazo ao trabalhador. Essas habilidades podem ser resumidas em duas palavras: atitude e versatilidade. (FENAPAES, 2007, p. 110)
\end{abstract}

As habilidades e competências estariam relacionadas, por exemplo, a autogestão de empreendimentos, bem como ao "[...] exercício do trabalho autônomo, individual e em grupo e a familiaridade com procedimentos para a melhoria da qualidade do trabalho e da capacidade produtiva" (FENAPAES, 2000 , p. 17). As bases para uma Educação Profissional de qualidade para as pessoas com deficiência deveriam levar em conta a concepção de homem engajado no seu tempo e consciente de sua realidade e responsabilidade social (FENAPAES, 2000, p. 41).

Nesse caso, para a FENAPAES, o "saber fazer" seria incisivo para ultrapassar os treinamentos associados ao fazer repetitivo, compreendendo uma formação profissional ao longo da vida. 
No campo da profissionalização, torna-se crucial ultrapassar meros treinamentos ligados ao fazer repetitivo, para atingir o saber fazer, unindo propedêutica, teoria e prática. Trata-se de redefinir a competência profissional moderna, tanto no sentido de vincular capacidade operativa com cidadania, como abrir caminho à competitividade e à qualidade. [...] Almejase uma formação profissional sem ponto final, ou seja, que não se completa, mas é contínua e atualizada [...]. É nessa perspectiva que se situa a formação baseada no desenvolvimento de competências, dando ao trabalhador conhecimento e formação profissional indutores de novas buscas de formação e constituição do sujeito [...]. (FENAPAES, 2007, p. 42)

As novas habilidades e competências dos trabalhadores estão associadas ao processo de reestruturação produtiva, o qual

[...] exige que se desenvolvam capacidades de comunicação, de raciocínio lógico-formal, de criatividade, de articulação de conhecimentos múltiplos e diferenciados de modo a capacitar o educando a enfrentar sempre novos e desafiantes problemas. Mais ainda, diante da velocidade das mudanças, as requalificações tornamse imperativas. (SHIROMA; MORAES; EVANGELISTA, 2002, p. 12)

Convergindo com Shiroma; Moraes; Evangelista (2002), Hotz (2010, p. 53) destaca que "[...] a qualificação não se dá em aspectos técnicos ou de formação básica, mas possui caráter ideológico e disciplinador, tendo mais natureza comportamental do que técnica".

Para a incorporação nas novas formas de produção destaca-se, desse modo, o modelo de competências, onde se afirma que o trabalhador deveria tê-las ou adquiri-las para permanecer empregado ou conseguir uma colocação no mercado de trabalho. A exigência de aquisição de competências tem um caráter ideológico, disciplinador e comportamental, cuja inserção social seria de sua responsabilidade individual. $O$ trabalhador procura a escola e os cursos profissionalizantes, almejando adquirir as competências e habilidades supostamente requeridas pelo mercado. Dessa forma, a educação também exerce a função ideológica de dissimular os mecanismos de discriminação presentes na sociedade. Dissemina-se a ideia de que, por meio dela, pode-se diminuir as desigualdades e de que cabe a cada um buscar a sua escolarização e qualificação, bem como alcançar a qualificação que o sistema produtivo propala como necessária. $O$ apelo à educação 
compõe o discurso ideológico da empregabilidade, ocultando a lógica da exclusão do sistema produtivo (HOTZ; ZANARDINI, 2009, p. 54-136).

Rosa (2009) também destaca o efeito ideológico da legislação que visa a inserção da pessoa com deficiência no mercado de trabalho formal, tanto no serviço público federal, quanto no setor privado. ${ }^{2}$

\begin{abstract}
Mesmo no caso do pequeno número das pessoas que estão trabalhando no mercado de trabalho formal, essas pessoas só são contratadas pela pressão do movimento das pessoas com deficiência e da existência da legislação que, apesar dos limites, neste caso, cumpre uma finalidade importante. A conclusão é a de que a legislação acaba produzindo mais um efeito ideológico do que propriamente prático, na medida em que transmite, para a sociedade em geral e para as próprias pessoas com deficiência, um argumento ideológico de que basta estar previsto em lei que o direito ao trabalho é uma realidade concreta. Isso acaba se revelando quando, após mais de 20 anos da promulgação da Constituição Federal de 1988, que garantiu a reserva de vagas, o índice de desemprego entre as pessoas com deficiência em idade de trabalhar ainda ultrapassa os $91 \%$, enquanto que, para as pessoas sem deficiência, gira em torno de $10 \%$. (ROSA, 2009, p. 171)
\end{abstract}

A FENAPAES, na perspectiva da inclusão, sustenta as inovações referentes a legislação que visa assegurar o acesso ao mercado de trabalho para a pessoa com deficiência.

As inovações na legislação que assegura os direitos das pessoas com deficiências ao mercado de trabalho têm aberto diferentes portas de acesso e permanência no trabalho, incluindo formas alternativas que favoreçam tanto as pessoas com comprometimentos leves, que podem ascender ao diversificado e restrito mercado competitivo, quanto as que, em razão de comprometimentos mais significativos, necessitam de apoio permanente na sua prática profissional. (FENAPAES, 2007, p. 118)

Os primeiros programas de treinamento vocacional e Educação Profissional surgiram na década de 1950 e não tinham uma preocupação direta com a inserção da pessoa com deficiência no mercado de trabalho. Todavia, visando ultrapassar o caráter ocupacional e terapêutico que a profissionalização nas APAES tinha até então (FENAPAES, 2007, p. 41), a partir de 1998, as APAES do Brasil iniciaram o desenvolvimento do chamado Processo de Educação Profissional e Colocação no Trabalho (PECT), com 
a oferta "serviços e programas no campo da Educação Profissional para iniciar, qualificar e incluir a pessoa com deficiência no mercado de trabalho" (FENAPAES, 1997, p. 09).

A oferta dos programas de Educação Profissional deveria identificar-se com a realidade sócio-econômica, sendo que as oficinas, cursos ou estágios, objetivariam ao aprendiz vivenciar e descobrir as suas habilidades, potencialidades e interesses, visando construir a autonomia e a independência pessoal. É importante destacar, também, o indicativo quanto ao bom desenvolvimento dos programas de educação profissional, o qual exigiria da instituição a constante atualização com o mercado de trabalho atuando, nesse caso, como articuladora das parcerias junto a órgãos públicos e empresas privadas (FENAPAES, 1997, p. 14-15).

A inserção da pessoa com deficiência, na década de 1990, está relacionada ao contexto de competição entre os trabalhadores e das novas exigências para o processo de produção. A aprovação e a efetivação da legislação que trata da inserção da pessoa com deficiência no mercado de trabalho formal, de maneira geral, seguiu a esteira mundial e colocou em evidência a preocupação educacional e social da pessoa com deficiência na referida década.

Portanto, a política de $\operatorname{cotas}^{3}$ e a política de Educação Profissional para a pessoa com deficiência são produzidas num contexto de "[...] reformas socioeconômicas, políticas e culturais introduzidas com as mudanças que ocorreram na esfera da produção capitalista, notadamente com o que se convencionou chamar de reestruturação produtiva, ou mudanças no mundo do trabalho" (ROSA, 2009, p. 14).

Conforme afirmamos, as mudanças que ocorreram na esfera da produção capitalista conferiram novas perspectivas e demandas para a reestruturação do ensino médio e profissional, ocorrido na segunda metade dos anos de 1990, sendo a Educação Profissional para a pessoa com deficiência redefinida a partir do discurso da valorização da qualificação. Nesse caso, seria preciso formar indivíduos com autonomia, criatividade, cooperação e responsabilidade necessárias às "novas formas de organização capitalista da produção" (DEITOS, 2005, p.131).

Constatou-se, desse modo, que os programas de Educação Profissional para a pessoa com deficiência, ao estarem inseridos na dinâmica do processo de reestruturação produtiva refletiram, em certa medida, as competências e as habilidades básicas exigidas para o trabalhador na 
década de 1990. Essa condição incluiria, por exemplo, os conhecimentos e competências específicas necessários para a profissão, a aquisição de atitudes e comportamentos desejáveis em qualquer trabalhador e as habilidades de gestão (FENAPAES, 1997, p. 29).

Anterior ao ano de 1997 as experiências de profissionalização ocorriam em algumas APAES de forma isolada, sem alcance nacional e sem um registro sistemático que pudesse ser conhecido e acessado por todo o Movimento Apaeano (FENAPAES, 2007, p. 99). Todavia, o ano de 1997 tornou-se um marco com a publicação do livro Educação Profissional e Colocação no Trabalho: uma nova proposta de trabalho Junto à Pessoa Portadora de Deficiência. Essa publicação se transformou num manual para auxílio teórico-prático do Processo de Educação Profissional e Colocação no Trabalho (PECT), com objetivo de planejar, executar e unificar a terminologia da Educação Profissional em todas as APAES do Brasil (FENAPAES, 1997, p. 10). Nesse contexto, conforme mencionamos, as APAES do Brasil incluíram "serviços e programas no campo da Educação Profissional para iniciar, qualificar e incluir a pessoa com deficiência no mercado de trabalho" (FENAPAES, 1997, p. 09).

No Movimento Apaeano, a implantação do Processo de Educação Profissional e Colocação no Trabalho (PECT), além de promover uma ressignificação de conceitos, proporcionou a quebra de paradigmas estigmatizastes que já estavam materializados. (FENAPAES, 2007, p. 100)

Para os profissionais envolvidos com o processo de Educação Profissional foram realizados, em 1998, cursos de Formação de Formadores, o qual se estendeu até 2001, quando o repasse de recursos do Ministério do Trabalho e Emprego (MTE) para a FENAPAES foi interrompido. "A indicação dos cursos seria de responsabilidade de cada estado, para entender e trabalhar com o novo modelo de Educação Profissional para pessoas com deficiência intelectual" (FENAPAES, 2007, p. 100).

Desse modo, a partir da implantação do Processo de Educação Profissional e Colocação no Trabalho (PECT), a FENAPAES buscou parceria nacional com o Ministério do Trabalho e Emprego (MTE), por meio do Plano Nacional de Qualificação do Trabalhador (PLANFOR), financiado pelo Fundo de Amparo ao Trabalhador (FAT). A destinação de grande parte de recursos do FAT era para o financiamento e amparo social do trabalhador e, principalmente, para a geração de programas de emprego e renda. Mas, com a evolução da crise social na década de 1990, especialmente retratada pela redução do número de postos de trabalho, foi concluído que boa parte 
dos recursos estava tendo outra destinação. "Foi no bojo da impotência dos programas de geração de emprego e renda, que o PLANFOR se fortaleceu e se afirmou como a mais visada política pública de emprego, entre 1995 e 2003, obscurecendo a sangria dos recursos do FAT" (CÊA, 2007c, p. 198).

E ao utilizar o PLANFOR, propondo qualificar e requalificar os trabalhadores de uma maneira rápida, desenvolvendo habilidades básicas, específicas e de gestão, ou seja, a lógica das competências exigidas para o novo mercado de trabalho, é que o país abraçou essa nova forma de dominação imposta pelo capital, precarizando ainda mais as relações de trabalho e aumentando significativamente o desemprego no Brasil (CEA, 2007, p. 192).

A crítica ao PLANFOR, por profissionais que trabalhavam com a Educação Profissional, sustentava-se no fato de que a política de Educação Profissional caracterizava-se apenas como um remédio para os males do desemprego, do subemprego e da precarização do trabalho (FENAPAES, 2007, p. 100).

Houve, também, manifestações em relação ao Decreto $n^{\circ}$. 2.208/97 no Congresso de Educação Profissional realizado em Brasília, no ano de 2003. Uns defendiam a revogação do decreto, outros propunham uma revisão, principalmente em relação ao Artigo $3^{\circ}$, Inciso I: "a qualificação, requalificação e reprofissionalização de trabalhadores, independente de escolaridade prévia" (FENAPAES, 1997, p. 90).

A FENAPAES, no que diz respeito às pessoas com deficiência intelectual e múltipla, destacou que

[...] tanto o PLANFOR como o Decreto $n^{\circ} 2.208 / 1997$ contribuíram de forma significativa para os profissionais da educação profissional especial, dando a eles poder de manobra, pois permitiam que os educandos com baixa escolaridade, em virtude da significância de suas deficiências, pudessem se capacitar e ser inseridos no mundo do trabalho. O PLANFOR contribuiu com diretrizes, dando elementos orientadores, naquela época, para a política de educação profissional adotada pelo Movimento Apaeano. (FENAPAES, 2007, p. 100)

Em 2003, o Ministério do Trabalho e Emprego anunciou a necessidade de se reformular a política pública de qualificação profissional e elaborou o Plano Nacional de Qualificação $(P N Q)^{4}$ com objetivo principal de 
[...] coordenar o desenvolvimento de ações de qualificação social, ocupacional e profissional dos trabalhadores e trabalhadoras, com ênfase na eficiência, eficácia, efetividade social, qualidade pedagógica, territorialidade e empoderamento, em articulação com as ações de intermediação, geração de emprego e renda, certificação e orientação ocupacional. (MORAES, 2005, p. 27)

Para o alcance do previsto acima, o Ministério do Trabalho e Emprego propôs "seis choques" (político, conceitual, institucional, operacional, pedagógico e ético) ou mudanças no campo da política pública de qualificação profissional, sendo que "pelo menos quatro deles, não representavam rupturas significativas em relação ao que vinha sendo proposto até 2003 pelo PLANFOR" (CÊA, 2007, p. 202). As dimensões conceitual e pedagógica poderiam estar apresentando algum avanço em relação ao PLANFOR, mas "tais avanços são relativos e de pouca expressão prática, considerando as necessidades e as defesas historicamente acumuladas pelos trabalhadores" (CÊA, 2007, p. 206).

Em 2004, a FENAPAES voltou a realizar uma parceria com o Ministério do Trabalho e Emprego por meio dos Projetos Especiais de Qualificação (ProEsQs). Esses projetos contemplavam a elaboração de estudos, pesquisas, materiais técnico-didáticos, metodologias e tecnologias de qualificação social, destinados a populações específicas (FENAPAES, 2007, p. 102).

No ano de 2005, a FENAPAES encaminhou um Projeto Especial de Qualificação (ProEsQ) para as entidades de todo o país. O objetivo desse projeto foi sistematizar as ações voltadas para a Educação Profissional ocorridas nas APAES do Brasil e publicar um livro com essa sistematização para servir de referência e modelo para as outras entidades brasileiras (FENAPAES, 2007, p. 102).

O projeto levou em consideração as seguintes ações contempladas pelo PNQ: desenvolvimento, experimentação, produção e avaliação de metodologias, tecnologias e materiais didáticos. Envolveu professores e coordenadores de educação profissional, de educação básica, educação de jovens e adultos, familiares, empresários, instituições de nível superior e a sociedade em geral. Todo esse processo foi dividido em etapas, identificadas com estratégias metodológicas que envolveram: estudos de caso, seminários, encontros regionais, reuniões de trabalho, sistematização, seleção de registros, validação de metodologias selecionadas e a 
publicação do livro 'Metodologias Aplicadas na Educação Profissional e Trabalho de Pessoas com Deficiência Mental e Múltipla'. (FENAPAES, 2007, p. 102)

A publicação do livro "Metodologias Aplicadas na Educação Profissional e Trabalho de Pessoas com Deficiência Mental e Múltipla" se tornou referência para todas as APAES filiadas na Federação Nacional. Os ProEsQs, desenvolvidos nas mais diferentes partes do Brasil, foram sistematizados e aplicados em outras regiões da Federação. "O objetivo do livro foi disseminar, em âmbito nacional, as metodologias que resultaram em experiências bem sucedidas de qualificação profissional e de geração de trabalho, emprego e renda de pessoas com deficiência mental, múltipla e seus familiares" (FENAPAES, 2005, p. 07).

É pertinente lembrar que no Brasil a Educação Profissional para as pessoas com deficiência foi oferecida, em grande parte, pelas instituições especializadas, como é o caso da APAE. Os programas de profissionalização foram assumidos por essas instituições ou organizações, devido ao fato de as pessoas com deficiência intelectual serem excluídas dos programas oferecidos por outras organizações públicas e privadas (ARAUJO, 2003, p. 140).

As novas relações de trabalho passaram a exigir a formação de habilidades e competências para as pessoas com deficiência, as quais deveriam disputar os postos de trabalho ocupados por outros trabalhadores, em situação de igualdade.

As novas relações de trabalho exigem habilidades e competências referentes ao pensar, decidir, trabalhar em equipe, entre outras. $\mathrm{Na}$ perspectiva da educação inclusiva, é necessário repensar essas práticas de forma a não preparar essas pessoas para o trabalho produtivo, mas também para disputar, em situação de igualdade, postos de trabalho ocupados por outros trabalhadores (FENAPAES, 2007, p. 118).

Dentre as exigências para o trabalhador com deficiência estaria a necessidade de formar para os "conhecimentos específicos" da ocupação ou profissão escolhida; para as competências específicas a serem colocadas em prática, quando do exercício da ocupação ou profissão escolhida; para o desenvolvimento de postura profissional, ou seja, da aquisição de atitudes e comportamentos desejáveis em qualquer trabalhador; e para as habilidades de gestão (FENAPAES, 1997, p. 29). 
Em síntese, pode-se dizer que o chamado Processo de Educação Profissional e Colocação no Trabalho (PECT) é resultado das transformações sociais, econômicas, políticas e educacionais que se intensificaram a partir da década de 1990, quando a Educação Profissional para a pessoa com deficiência foi redefinida a partir do discurso da valorização da qualificação. Nesse caso, compreenderia a formação de indivíduos com autonomia, criatividade, cooperação e responsabilidade necessárias às "novas formas de organização capitalista da produção" (DEITOS, 2005, p.131), conforme afirmado. Os programas de Educação Profissional para a pessoa com deficiência, ao estarem inseridos na dinâmica do processo de reestruturação produtiva refletiram, em certa medida, as competências e habilidades básicas exigidas para o trabalhador na referida década.

\section{Referências}

ARAÚJO, E. T. de. Inclusão como missão: reflexões sobre as mudanças na gestão da educação profissional em instituições especializadas. In: Trabalho e deficiência mental: Perspectivas atuais. APAE, Dupligráfica, Brasília, 2003.

BRASIL. FENAPAES - FEDERAÇÃO NACIONAL DAS APAES. Educação profissional e colocação no trabalho: uma nova proposta de trabalho junto à pessoa portadora de deficiência. Um manual para profissionais e dirigentes. Brasília, FENAPAES, 1997.

Educação Profissional. Competências e estratégias para implantação e/ou implementação das etapas de preparação, qualificação e colocação de pessoa portadora de deficiência no mundo do trabalho. Coordenadoria de Educação Profissional. Brasília, 2000.

Metodologias aplicadas na educação profissional de pessoas com deficiência mental e múltipla. FENAPAES, Brasília, 2005.

Educação profissional e trabalho para pessoas com deficiências intelectual e múltipla. Plano orientador para gestores e profissionais. FENAPAES, Brasília, 2007.

CÊA, G. S. dos S. A qualificação profissional como instrumento de regulação social: do PLANFOR ao PNQ. In: CÊA, Geórgia S. dos Santos (Org). O Estado da arte da formação do trabalhador no Brasil: pressupostos e ações governamentais a partir dos anos 90. Cascavel, Edunioeste, 2007.

DEITOS, R. A. Ensino médio e profissional e seus vínculos com o BID/ BIRD: os motivos financeiros e as razões ideológicas da política educacional. Cascavel, EDUNIOESTE, 2001. 
DEITOS, R. A. O capital financeiro e a educação no Brasil. Campinas, UNICAMP, 2005. (Tese de Doutorado).

DELORS, J. Educação: um tesouro a descobrir. 4. ed., São Paulo, Cortez; Brasília, MEC, UNESCO, 2001.

HOTZ, K. G. Avaliação da implementação do PROEJA em municípios do oeste do Paraná (2008 - 2009). UNIOESTE, Cascavel, 2010. (Dissertação de Mestrado).

HOTZ, K. G.; ZANARDINI, I. M. S. Implicações do processo de reestruturação produtiva no Brasil para os trabalhadores e a educação: algumas considerações. In: Práxis Educativa, Ponta Grossa, v.4, n.2, p.131138, jul.-dez. 2009. Disponível em: <http://www.periodicos.uepg.br>. Acesso em: 02 nov. 2010.

MOARES, E. L. de. Construindo identidades sociais - Relação gênero e raça na política pública de qualificação social e profissional. V. 1. Brasília: MTE, SPPE. DEQ, 2005.

NAGEL, L. H. Condições de educabilidade para uma nova sociedade: reflexões básicas. In: Germinal: Marxismo e Educação em Debate, Londrina, v. 2, n. 2, p. 54-68; ago. 2010.

ROSA, E. R. da. O trabalho das pessoas com deficiência e as relações sociais de produção capitalista: uma análise crítica da política de cotas no Brasil. UNIOESTE, Cascavel, PR: [s.n.], 2009. (Dissertação de Mestrado).

SHIROMA, E. O., MORAES, M. C. M. de; EVANGELISTA, O. Política Educacional. Rio de Janeiro: DP\&A, 2002.

\begin{abstract}
Notas
${ }^{1}$ Oficina protegida é uma alternativa de atendimento para as pessoas com deficiência intelectual e múltipla, que, devido a significância de sua deficiência, não apresentam condições de inserção nos programas de qualificação profissional e nos programas de colocação no trabalho. Essa oficina é um programa mais específico, onde o aluno passa o tempo fazendo atividades práticas (como artesanato, pintura, costura, etc.), e atividades esportivas e culturais, para suprir suas necessidades sociais, emocionais, educacionais e ocupacionais (FENAPAES, 2007, p. 141).

${ }^{2}$ Trata-se da Lei $n^{\circ} 8.112$, de 11 de dezembro de 1990, e da Lei n 8.213 , de 24 de julho de 1991.

${ }^{3}$ Rosa (2009, p. 236) reconhece que as políticas sociais, principalmente a política de cotas, que estabelece a reserva de vagas para as pessoas com deficiência, dado o seu caráter compensatório, na sua essência não vai além das reformas nas aparências do capitalismo. Todavia, também pondera que a Política de Cotas, para a inserção das pessoas com deficiência no mercado de trabalho público e privado, foi importante para a luta histórica que elas travaram com a sociedade como um todo.
\end{abstract}

Revista Educação Especial | v. 26 | n. 45, | p. 59-72 | jan./abr. 2013

Santa Maria

Disponível em: <http://www.ufsm.br/revistaeducacaoespecial> 
Ireni Marilene Zago Figueiredo - Jackson Johann

4 "Em relação às políticas de qualificação, iniciado com a implementação do Plano Nacional de Qualificação (PLANFOR), o mesmo foi transformado em Plano Nacional de Qualificação (PNQ). [...] A partir de agosto de 2003, em função da ascensão ao poder de uma nova coalizão política, o PLANFOR foi substituído pelo PNQ" (CEA, 2007, p. 187).

\section{Correspondência}

Ireni Marilene Zago Figueiredo - Universidade Estadual do Oeste do Paraná, Centro de Educação Comunicação e Artes, Departamento de Educação - Rua Universitária, 1619 - Jd. Universitário - Jd. Universitário, CEP: 85814-110 Cascavel, Paraná, Brasil - Caixa-postal: 801.

E-mail: irenifigueiredo@hotmail.com - jacksonjohann@hotmail.com

Recebido em 29 de outubro de 2011

Aprovado em 23 de julho de 2012 